\title{
Evaluation of the Accessibility of Selected Packaging by Comparison of Quantitative Measurements of the Opening Forces and Qualitative Surveys through Focus Group Studies
}

\author{
By Susanna Wenk, ${ }^{1}$ Christine Brombach, ${ }^{1}$ Gràcia Artigas, ${ }^{2}$ Eila Järvenpää, ${ }^{3}$ \\ Nina Steinemann, ${ }^{1}$ Katrin Ziesemer ${ }^{1}$ and Selçuk Yildirim ${ }^{1 *}$ \\ ${ }^{1}$ Life Sciences and Facility Management, Zurich University of Applied Sciences, Campus Reidbach, 8820 Waedenswil, \\ Switzerland \\ ${ }^{2}$ Emporhotel A.I.E., C/Hospital, 27, 2on, 1a, 17230 Palamós, Spain \\ ${ }^{3}$ Natural Resources Institute Finland, Alimentum (Myllytie 1), 31600 Jokioinen, Finland
}

It can be expected that many elderly people have impaired opening capacity of food packaging bearing in mind the changes in functionality and physical strength that occur during ageing. This study determined the relation of the quantitative force required to open selected food packaging systems with findings derived from qualitative focus group studies to retrieve comprehensive information on the specific needs of seniors. The focus group studies revealed that the assessment of the ease of opening is very subjective and can vary from objective measurements. The quantitative measurement of the force required to open the 'easy to open' thermoformed tray resulted in considerably higher peel initiation forces of $22.50 \pm 1.62 \mathrm{~N}$ compared to the standard tray $(12.80 \pm 1.93 \mathrm{~N})$. However, the packaging type was still felt to be easier to open because of the enlarged tab and peeling corner, which was said to be easy to grip. Conversely, the stand-up pouches with twist-off caps could only be opened with difficulty because of the small caps and the difficulty in breaking seals, despite the substantially lower opening forces of $0.46 \pm 0.06 \mathrm{Nm}$ compared with the other torque closures. The evaluation of a package was found to be only partly dependent on the required opening force but strongly influenced by various design factors and consumer's expectations as well as experiences. Copyright (C) 2016 John Wiley \& Sons, Ltd.

Received 28 November 2014; Revised 19 May 2016; Accepted 18 July 2016

KEY WORDS: easy to open packaging; opening force; quantitative measurements; focus group studies; openability

\section{INTRODUCTION}

Packaging is an inevitable aspect of today's industrialized food production and retailing. Packaging systems maintain the microbiological, nutritional and sensory quality of the packaged product, enhance its safety and thereby extend the shelf life of a product. Consumers expect packaging to be functional and to satisfy their specific needs in every respect. Needs and consumer behaviour change during the course of life. ${ }^{1}$ The single fastest growing demographic, that of the older consumers over 65 years, indicates that there will be shifts in consumer demand. It is important for food retailers and producers to meet the needs of a growing market segment, which involves understanding consumers' preferences and choices. Consumers' choice of food and their purchase decisions are determined by the perceived functionality, and the openability, legibility and manageability of food packages. ${ }^{2,3}$

Changes in functionality and physical strength occur during aging. Some of the best known symptoms of old age are the decrease in muscle strength and muscle mass. ${ }^{4}$ Geriatric research has

\footnotetext{
* Correspondence to: Selçuk Yildirim, Life Sciences and Facility Management, Zurich University of Applied Sciences, Campus Reidbach, 8820 Waedenswil, Switzerland.

E-mail: selcuk.yildirim@zhaw.ch
} 
demonstrated that advancing age results in loss of strength and dexterity, restricted motility of the joints, pain-sensitive skin and difficulties encountered when applying pressure with the hands. ${ }^{5}$ Hand grip strength was shown to be a general predictor of overall health and strength in later life, a decline indicating a higher risk of becoming dependent. ${ }^{6-8}$ In addition to hand force, a variety of functional restrictions of the tactility ${ }^{9}$ as well as of the visual capacity ${ }^{10-13}$ and of cognitive aspects ${ }^{14-16}$ occur in old age.

Physical transformations create challenges and hurdles for elderly consumers when opening food packaging systems that require reading, handling, gripping and pulling. ${ }^{9,17}$ Many complaints from the elderly and the difficulties they encounter when opening food packaging have been reported in the literature. ${ }^{1,18-21}$ A study conducted by Pro Carton ${ }^{19}$ found that $81 \%$ of the elderly people questioned were only partly satisfied or even completely dissatisfied with commonly used packaging. Product information that is hard to read, vague or even absent, opening mechanisms that are incomprehensible, and packaging that is difficult to open and difficult to reclose were the main problems identified. ${ }^{1,19}$ Poor understanding of the packaging and physical limitations may increase the possibility of injuries and accidents when opening, reclosing, emptying or disposing of more challenging types of food packaging. ${ }^{17,21-23}$

The kind of grips and the forces that need to be applied for package opening vary according to the type of packaging and the ability of the consumers. According to Schreib et al. ${ }^{24}$, package opening can be divided into three main gripping activities: pulling, pushing and twisting. Each activity requires different consumer capacity, strength and ability and depends on the physiologically available and applicable strength. Packaging systems frequently call for combinations of the various activities, thereby demanding different kind of grips and forces. The capacity to open food packaging was found to depend on the kind of grip, hand and arm positioning, interplay of surface of package and hand, age, sex and muscle strength of the individual..$^{20,24-26}$

Different research has been carried out in the field of openability of packaging. Packaging systems with torque closures ${ }^{18,27,28}$ as well as peelable trays, ${ }^{24,29,30}$ which require a coordinated two-handed process, were found to be particularly challenging. However, most of the work undertaken contained the measurement of the wrist twisting strength for medium-sized torque closures. ${ }^{27,31-35}$ On the basis of the implemented studies, efforts are made to reduce the opening forces of packaging and thus to make them accessible to different demographic groups. Nevertheless, studies providing comprehensive data of quantitative analysis of the opening forces of various food packaging systems and its contrast to qualitative results are not yet widespread.

The specific aim of this study was to retrieve comprehensive information on the accessibility of food packaging systems with reference to seniors over 65 years of age. For this purpose, findings derived from qualitative focus group discussions were compared with quantitative measurements of the opening force of selected packaging.

\section{MATERIALS AND METHODS}

\section{Packaging types used in the study}

Ten food packaging systems with variations of the most common opening mechanisms used for regularly consumed food items available on the market were selected for evaluation by elderly people in focus group studies. The selection covered the main gripping activities twisting, pulling and pushing and included four torque closure products with varying diameters; two pouches, one openable by ripping along indentations and one openable by two-handed ripping of a sealed seam; two different types of thermoformed trays and a container with peelable tabs; and one ring-pull can. The exact dimensions of the different packaging types were predefined to ensure corresponding examples of packaging in each country involved in the study were evaluated. The 10 packaging types chosen are specified in Table 1.

\section{Measurement of the opening forces of the packaging}

Physical measurement of the force needed to open the package was carried out in a 20-fold determination with the packaging examples from Switzerland at room temperature. Peel initiation force, 
Table 1. Packaging types used in the study (photographs represent the packages used in Switzerland).

Packaging systems with torque closure

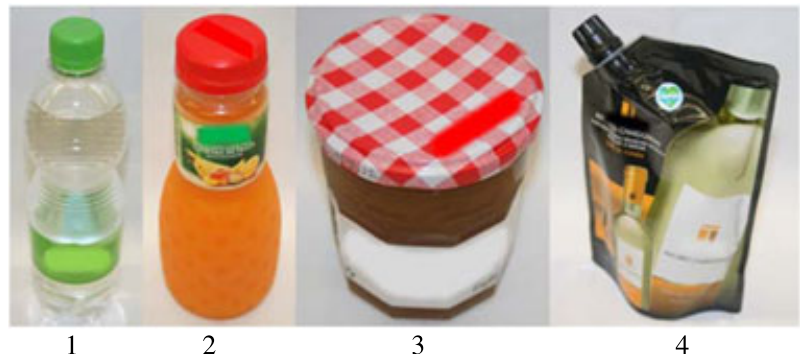

1

2

Dimensions of the screw cap:

- Total height: $2.1 \mathrm{~cm}$

- Diameter: $3.0 \mathrm{~cm}$

$2 \quad$ PET bottle with a larger screw cap and underneath a peelable aluminium foil with tab

Dimensions of the screw cap:

- Total height: $1.7 \mathrm{~cm}$

- Diameter: $4.0 \mathrm{~cm}$

$3 \quad$ Jar with twist-off lid

Dimensions of the lid:

- Height: $1.0 \mathrm{~cm}$

- Diameter: $8.5 \mathrm{~cm}$

$4 \quad$ Stand-up pouch with twist-off cap

Dimensions of the twist-off cap:

- Length: $1.9 \mathrm{~cm}$

- Diameter: $1.4 \mathrm{~cm}$

Peelable packaging and cans

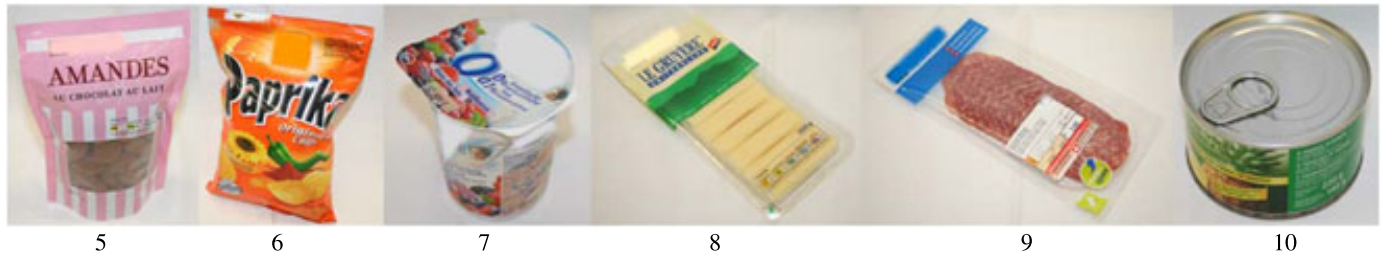

$5 \quad$ Stand-up pouch with a small indentation on each side

Width of the pouch: $10.9 \mathrm{~cm}$

Dimensions of the indentation:

- Distance from the top: $2.0 \mathrm{~cm}$

- Width of the indentation: $0.2 \mathrm{~cm}$

6 Metallized pouch with sealed seam at the upper edge

Width of the pouch: $17.3 \mathrm{~cm}$

Width of the sealed seam: $1.2 \mathrm{~cm}$

$7 \quad$ Thermoformed tray

Dimensions of the tab:

- Length: $0.7 \mathrm{~cm}$

- Diagonal: $1.3 \mathrm{~cm}$

8 Thermoformed tray 'easy to open'

Dimensions of the tab:

- Length: $1.5 \mathrm{~cm}$

- Diagonal: $3.5 \mathrm{~cm}$

$9 \quad$ Container with aluminium foil lid

Diameter of the container: $7.0 \mathrm{~cm}$

Dimensions of the tab:

- Length: $1.2 \mathrm{~cm}$

- Diagonal: $2.8 \mathrm{~cm}$

10

Ring-pull can

Diameter of the can: $8.5 \mathrm{~cm}$

Dimensions of the key:

- Length: $3.7 \mathrm{~cm}$

- Diameter: $2.4 \mathrm{~cm}$

average peeling force and the ultimate peel force of the peelable packages were determined conforming to DIN 55409-1 (flexible packaging) and DIN 55409-2 (dimensionally stable packaging) using a material testing machine (Zwicki-Line 500N, Zwick GmbH \& Co. KG, Ulm, Germany). The 
packaging was fixed with clamps, and the opening process was simulated through a tensile test at defined speed and tear angle conforming to DIN standard. The packaging was moved at the same rate to guarantee a constant tear angle over the entire opening length. Packaging types with a torque fastening were measured with a manually operated digital torque tester (Tornado, Emperor Lite Software, Mecmesin GmbH, Schwenningen, Germany). The package was clamped on a versatile mounting table, and the necessary torque to open the packaging was applied by fixing the fastening by hand, while the device was rotated at a test speed of $12 \mathrm{rpm}$.

The determination of the opening force along the entire length of the packaging was recorded in a force-length diagram.

\section{Implementation of focus group studies}

Participants. Two focus group sessions were conducted in Finland, Spain and Switzerland each. The countries were chosen based on their geographical location in Northern, Central and Southern Europe to determine cultural-specific assessments. The elderly people were recruited based on physical characteristics: 'active elderly' were defined as persons over 65 years old living independently, without any private health assistance and not using a meal service. Based on a pragmatic approach, this reflects the concept that cooking requires the daily activities that may be affected because of the functional capabilities in aging. ${ }^{36}$ Thus, a senior being 'active' implies a certain amount of ability and self-care. 'Unfit or frail elderly' were described for the purposes of this study as being those elderly over 65 years of age living independently but in need of a daily meal service or alternatively living in residential care homes or retirement homes. This follows the concept that some activities of daily living are impaired because of functional decline during ageing. No specific sampling technique instruction was applied because qualitative methods do not focus on representative sampling. A total of 62 participants from all three countries were invited to the focus group sessions. With an average age of 81.5 (65-101) frail elderly ( $25 \%$ men and $75 \%$ women) were typically older than active elderly ( $44 \%$ men and $56 \%$ women) who had an average age of 71.3 (66-81).

Approach. The focus group studies in all three countries were conducted accordingly. Prior to sessions, written informed consent and written, signed permission to take videos were obtained from all participants, and participants were asked to complete a general questionnaire upon arrival. The food packaging samples for assessment were introduced individually, one after the other, and discussions were held. The focus groups were moderated by a researcher following a rough guideline referring to the general handling of the packaging, the identification of the opening mechanism, the description of the opening procedure and the actual opening of the packaging, to ensure comparability between active and frail elderly and the different countries. Sufficient time was given to ensure that all points of interest were thoroughly addressed. The packaging remained in front of the participants on the table during the focus group sessions to allow for ranking and comparison of all different food packaging systems in the final discussion round. A protocol was written during the session, and videos of participants handling food packages were recorded during the whole session with two cameras positioned to video from various angles.

Analysis. The main focus of the analysis of the data was on thematic content of the discussions, but ethnographic aspects were also assessed. The analysis was performed by three researchers who were trained by reference to a category analysis system prior to conducting focus groups and the collaborative evaluation of the video sequences. After consensus had been reached on the most important observations, they were cross-checked with the written protocol taken during focus group discussion. This approach was applied to all food packaging systems and for both focus groups, active and frail elderly. The results were cross-checked by an additional researcher who proceeded independently in the same manner. These measures were undertaken to try to ensure the quality of the data and followed an ethnographic approach to get an in-depth understanding of the meanings and actions, and stories and narratives from the videos throughout the data-analysing process. The observed and detected topics and themes of each country were then combined.

Hand force measurement. Hand force measurements were conducted on the 18 Swiss participants, 10 active elderly with an average age of 72.8 (70-81) and 8 frail elderly with an average age of 83.7 (70-93), using a sensor handle (Pablo® System, Tyromotion GmbH, Graz, Austria). The computerized 
multi-purpose device enabled measurement of the hand force with various types of grips needed to open the selected packages. The device was calibrated by zero adjustment of the force sensor. Cylindrical grip, pinch grip and lateral pinch were measured in duplicates for both categories of elderly people. The trial was performed using the standard testing position: sitting with the arm bent at a $90^{\circ}$ angle.

\section{RESULTS AND DISCUSSION}

\section{Quantitative measurements of the opening forces of the packaging types}

The physical measurement of the force needed to open the different packaging examples is shown in Table 2.

For the four packaging systems with torque closure, different opening forces were quantified depending on the type of closure and its diameter (Table 2). The Polyethylene terephthalate (PET) bottles with screw cap showed variable opening force progressions. Long unscrewing of the cap was necessary, and individual high force peaks occurred. Measurements revealed a starting torque of 1.54 $\pm 0.19 \mathrm{Nm}$ before the screw cap of the PET bottle could be opened with an average torque of 0.56 $\pm 0.05 \mathrm{Nm}$. Opening of PET bottles with larger screw caps required considerably lower starting torques $(0.58 \pm 0.10 \mathrm{Nm})$ and average torques $(0.26 \pm 0.04 \mathrm{Nm})$ compared with those of standard PET bottles (Figure 1). The short thread of the cap necessitated only short unscrewing, and the force progression was much more consistently for all measurements. The aluminium foil underneath the screw cap could be peeled with an initial force of $6.07 \pm 2.23 \mathrm{~N}$ (ultimate peel force of $16.23 \pm 3.37 \mathrm{~N}$ and average peeling force of $6.64 \pm 1.26 \mathrm{~N})$. The highest starting torques $(6.08 \pm 0.51 \mathrm{Nm})$ and average torques $(2.52$ $\pm 0.40 \mathrm{Nm}$ ) were obtained when opening jars with twist-off lids to remove the reduced pressure and to loosen the lid. The torque measurements of the stand-up pouch twist-off cap revealed that the starting torque of $0.46 \pm 0.06 \mathrm{Nm}$ and the average torque of $0.13 \pm 0.02 \mathrm{Nm}$ were low compared with the other torque covers.

For peelable packaging, the peel initiation force, the ultimate peel force and the average peeling force were quantified (Table 2). The opening force of the two examined pouches differed greatly. The strength required to open the selected stand-up pouch along the indentations was rather low with a peel initiation force of $8.69 \pm 2.15 \mathrm{~N}$ equaling the ultimate peel force, and an average peeling force of $2.62 \pm 0.28 \mathrm{~N}$. Measurements of the opening force of the metallized pouch on the other hand revealed much higher initial forces of $20.94 \pm 2.32 \mathrm{~N}$ (equivalent to ultimate peel force) were needed to tear open the sealed seam with a tear angle of $180^{\circ}$, while the average peeling force was $7.16 \pm 0.55 \mathrm{~N}$.

The physical measurements of the opening force of the thermoformed tray resulted in rather high values of $12.69 \pm 2.04 \mathrm{~N}$ for the peel initiation force, $17.97 \pm 1.68 \mathrm{~N}$ for the ultimate peel force and an average peeling force of $9.29 \pm 0.63 \mathrm{~N}$. Considerably higher forces of $22.49 \pm 1.62 \mathrm{~N}$ for the peel initiation force, $30.49 \pm 4.39 \mathrm{~N}$ for the ultimate peel force and $11.70 \pm 0.48 \mathrm{~N}$ for the average peeling force were determined when opening the thermoformed 'easy to open' tray (Figure 2). Nevertheless, it was apparent that unlike the standard thermoformed tray, the opening force progression was almost identically for all measurements. Tearing-off of the foil demanded the maximum force when opening the two types of trays. However, as usage of a tray does not necessitate tearing-off of the top film, the peel initiation force is more critical for the openability.

A different opening behaviour could be observed in the container with aluminium foil lid. Force had to be applied mainly for the peel initiation of the lid $(13.88 \pm 1.24 \mathrm{~N})$, which often was the ultimate peel force $(14.16 \pm 1.02 \mathrm{~N})$, while the average peeling force along the entire packaging was $5.53 \pm 0.75 \mathrm{~N}$.

The measurement of the opening force of the ring-pull can consist of two sub-steps (Table 2). The maximum force needed to pull up the pull ring of the can to the top was found to be $49.51 \pm 10.32 \mathrm{~N}$ (average force $12.80 \pm 2.07 \mathrm{~N}$ ). Because of the limitations of the material testing machine, the pullingoff of the lid could not be measured.

\section{Focus group studies}

Hand force of the participants. The results of the measurements of the cylindrical grip, pinch grip and lateral pinch of the 18 participants are shown in Table 3. The cylindrical grip allowed higher 


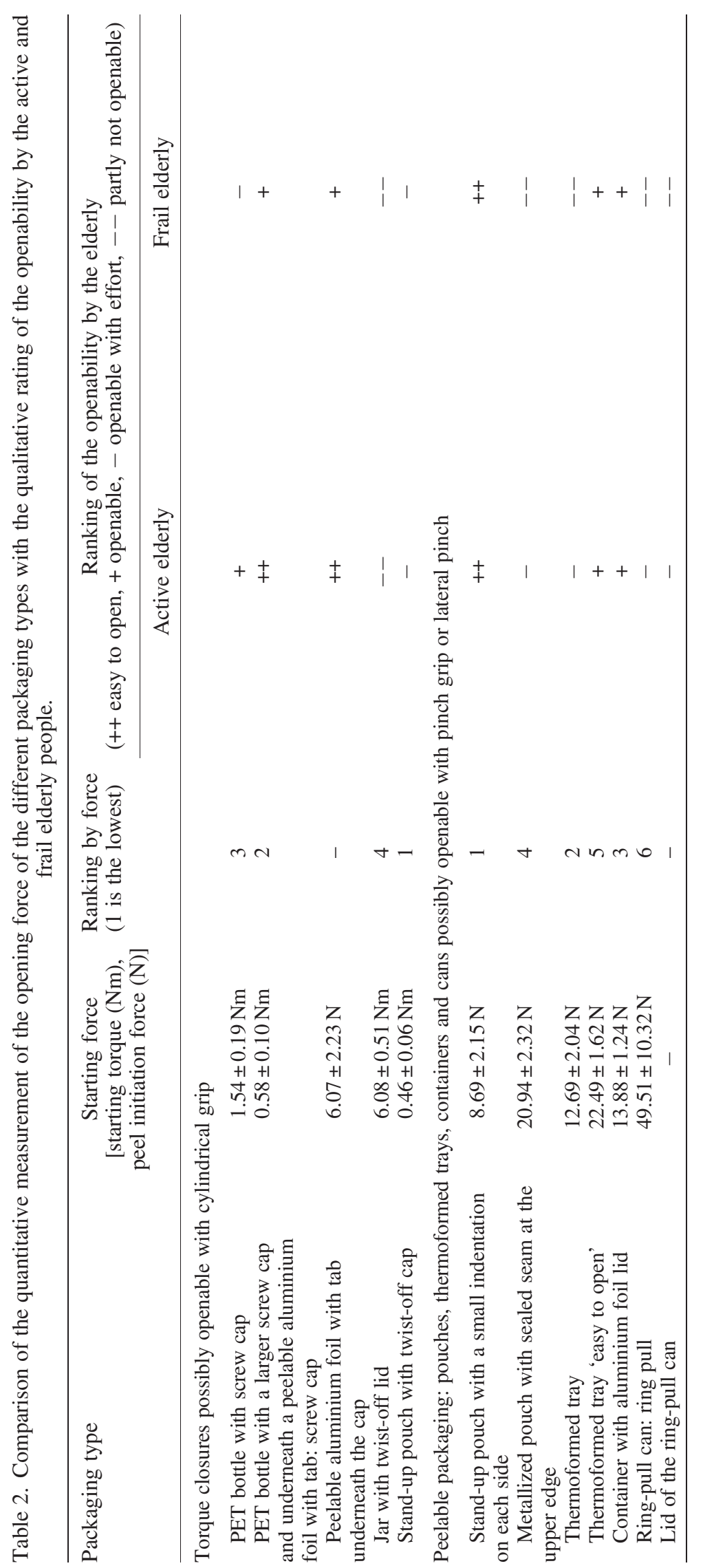




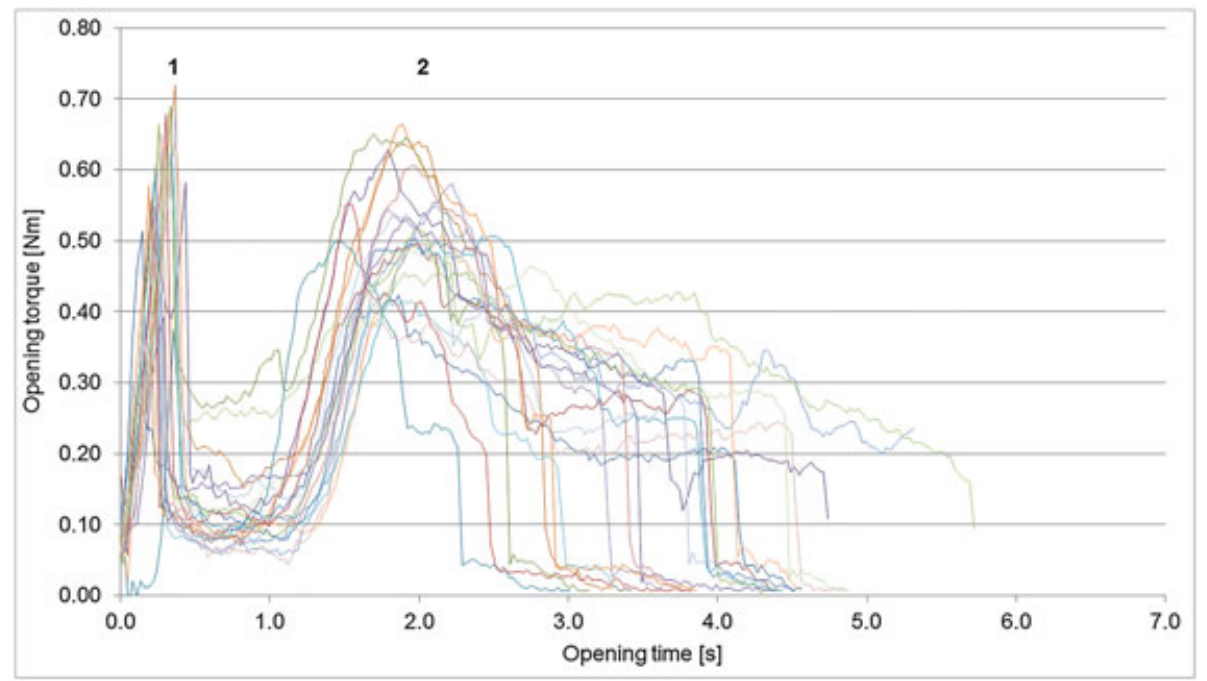

Figure 1. Opening force progression of PET bottles with a larger screw cap diameter of $40 \mathrm{~mm}$ and underneath a peelable aluminium foil with tab with (1) the starting torque and (2) the detachment of the cap.

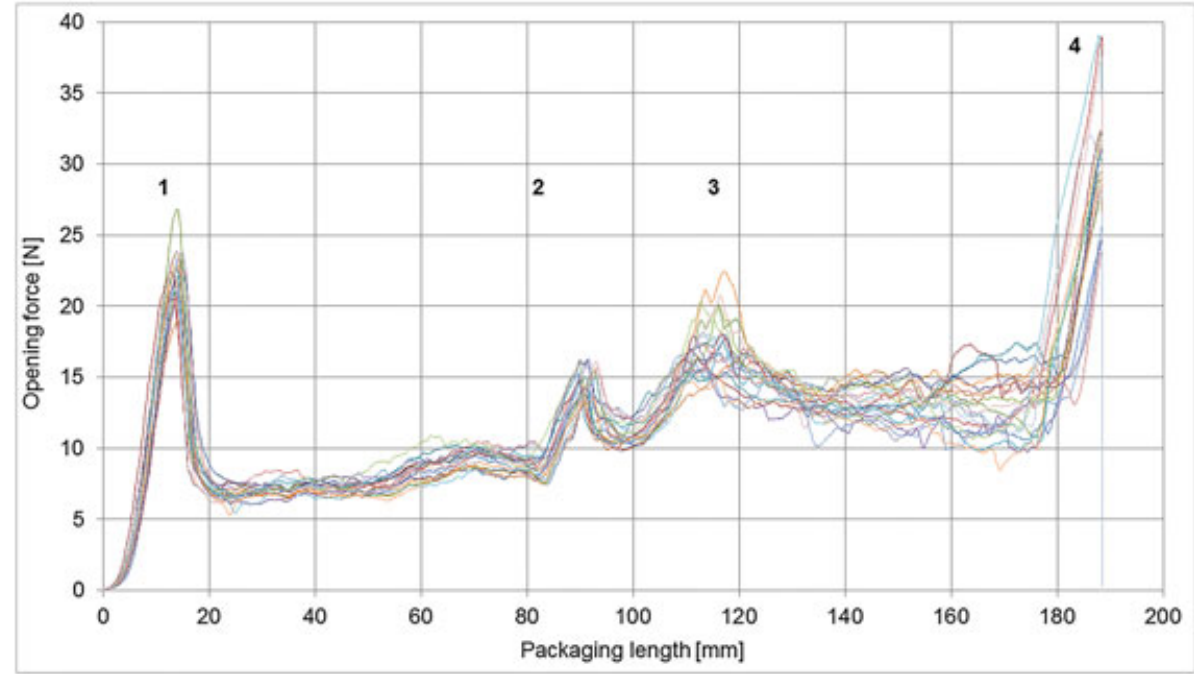

Figure 2. Opening force progression of thermoformed trays 'easy to open' with (1) the peel initiation force, (2) and (3) an increase of the opening force at the corners of the packaging and (4) the tearing-off force, which in this case equals the ultimate peel force.

Table 3. Measurements of the cylindrical grip, pinch grip and lateral pinch of the Swiss focus group participants.

\begin{tabular}{|c|c|c|c|c|c|c|}
\hline \multirow[t]{2}{*}{ Category } & \multicolumn{2}{|c|}{ Cylindrical grip } & \multicolumn{2}{|c|}{ Pinch grip } & \multicolumn{2}{|c|}{ Lateral pinch } \\
\hline & Average $[\mathrm{N}]$ & Range [N] & Average $[\mathrm{N}]$ & Range $[\mathrm{N}]$ & Average $[\mathrm{N}]$ & Range $[\mathrm{N}]$ \\
\hline Active elderly $(n=10)$ & 229.2 & $106.0-384.2$ & 69.7 & $31.9-130.7$ & 76.4 & $41.8-138.6$ \\
\hline Frail elderly $(n=8)$ & 152.9 & $63.7-264.3$ & 43.7 & $15.9-74.1$ & 57.2 & $28.4-99.7$ \\
\hline
\end{tabular}


strength than the pinch grip or the lateral pinch. The average values for each grip type were indicative of a slight tendency that frail elderly possessed lower hand forces than active elderly. However, a wide range of hand strength was found between the individuals. A difference of $278.2 \mathrm{~N}$ was present between the highest and lowest value of the cylindrical grip in active elderly.

Evaluation of the packaging types. The difficulties and barriers of elderly people with packaging were determined by means of focus group studies. No country-specific differences were found between the countries Finland, Spain and Switzerland. Although the degree of familiarity of the 10 food packaging systems differed in the three countries, similar problems, needs and expectations were expressed by all elderly people.

Packaging systems with torque closure. The packaging with torque included in this study were all very well known and established in the three countries and as a result perceived as comfortable and a 'good' packaging. The assessment of opening procedure still differed between the two categories of elderly people, as well as for the different packaging types. While the groups of active elderly had no problems opening the package, frail elderly shared the experience that screw caps may be hard to loosen. Opening of the standard bottle required excessive strength, with some subjects reporting problems like sore hands or spilling of the bottle's content. The opening of the bottle with a larger screw cap was conversely described as much easier than anticipated. The participants of the focus group studies noticed that the cap of the examined PET bottle with a larger screw cap could be more easily gripped and turned, due to its slightly larger diameter as well as its deeper grooves. The additional peelable foil underneath the screw cap was viewed very positively as a guarantee of quality.

The diameter of the twist-off lid of the jar was perceived as rather large, especially for women. During focus group discussions, many participants had various experiences to tell and shared tips and tricks as how to best open a tight jar with aids like bottle openers, kitchen scissors, screwdrivers or hot water. It was well accepted that jars are tightly closed, 'that is what they are made for' as a participant commented. The frail elderly in particular had problems applying the necessary force, and about half of the group indicated that tools were needed to open the packaging and did not manage to open the jar.

Unlike the other packaging types with torque closure, stand-up pouches with twist-off caps were partly known from refill bags for bath gel or detergent yet were a totally unknown packaging system for food. The opening mechanism seemed to be clear to everybody, but the statements concerning the actual opening of the packaging varied widely. The group of frail elderly could only open the packaging with much effort. The cap was criticized as being too small to afford a secure grip, and the seal was said to be difficult to crack. Discussions revealed that some panelists felt insecure when handling this type of packaging.

Peelable packaging: pouches, thermoformed trays and containers. Pouches were principally a familiar packaging system. However, not everybody was accustomed to the varying forms and the considerable differences in the opening forces.

The participants were only partly acquainted with stand-up pouches with small indentations on each side and thus felt uneasy in the use of such packaging at the very beginning. However, the packaging was assessed as user-friendly and pleasurable because the indentations were well marked and as opening was achieved with an easy grip and with rather low force that was generally applicable from both active and frail elderly. Many of the elderly stated that they would use scissors at home to open this kind of packaging to get a neat opening.

In the case of metallized pouches with sealed seams, participants were inexperienced with the opening principle of symmetrical pulling on the side areas of the pouch. Marking of the opening mechanism or even instructions for the opening approach were lacking, and the elderly people used very individual strategies to tear open the packaging. Particularly, the frail elderly exhibited greater difficulty in exerting the necessary force and a strong lateral pinch with both hands. The initial force required to open this type of pouch may result in a difficult and unpredictable opening procedure with a sudden rip of the sealed seam and thus the risk of spilling the contents. Several elderly people did not manage to open the sealed pouch at all. 
The evaluated thermoformed trays and containers were very popular in all three countries and regularly used by participants of the focus groups. Light, handy and available in various sizes, thermoformed trays were mainly related to sliced cheese or meat products. Despite the familiar packaging system, the identification of the opening mechanism was found to be greatly dependent on the visibility of the tab of the tray. As many elderly had bad experiences with opening trays, certain concerns were expressed as to whether the packaging could be opened. Typically, scissors or knives were often used as an opening tool. The actual opening was then rated very differently depending on the type of packaging and the physical condition of the elderly people. Controlling of the pinch grip or lateral pinch and application of force at the same time to open the standard thermoformed tray was a challenge, especially among frail elderly of the focus groups. Peelable packages were assessed as often having rather small tabs to grip but high peel initiation forces. The Swiss thermoformed 'easy to open' tray was felt to be easier to open because of the enlarged tab and peeling corner, which was said to be easy to grip.

When opening the container with the aluminium foil lid, force had to be applied mainly for the first ripping and the tearing-off. A protruding tab improves the access ${ }^{29}$ and was highly appreciated by the elderly people of the focus groups.

Cans. Cans, particularly ring-pull cans, are a well-known packaging system in every country, and the concept of the ring-pull opening mechanism was clear to everybody. However, the packaging type was strongly associated with negative experiences. Problems like breaking off of the pull ring, sore fingers because of sharp edges on the ring or injuries due to sharp lid rims were described. A very individual handling of the opening mechanism was revealed in the focus group studies. The active elderly documented the opening as difficult, very exhausting and were afraid to hurt themselves but could all open the can. Hence, there was a clearly recognizable difference between the two categories of elderly people in all countries. Opening of the ring-pull can necessitates pushing up the ring pull and pulling the lid open successively. ${ }^{24}$ This complex process demands great dexterity as well as enough strength from the seniors. Opening procedures that require excessive hand actions may inhibit elderly peoples' ability to open a package. ${ }^{17}$ Particularly, the frail elderly among the participants had great difficulties in providing the required initial force and the hand skills simultaneously, and only part of the participants managed to just pull up the ring pull of the can, and still fewer could fully open the packaging.

\section{Comparison of the quantitative force measurements with the qualitative assessments of the openability} of the packaging

The quantitative measurements of the evaluated packaging types were contrasted with the qualitative survey to apprehend if the subjective perceptions of the openability are related to the force required to open a package (Table 2). The comparison was based on the starting force that was found to be critical for the opening of each examined packaging system.

Packaging systems with torque closures were found to be generally regarded as being particularly challenging. Several other studies have already shown that although the opening mechanism of the packages is familiar, elderly consumers might not be successful in opening the packaging just because they are unable to exert sufficient force. ${ }^{9,17,27,37}$ Packaging types with torque usually involve both hands, the non-dominant hand that holds the packaging and provides the counter pressure and the active hand that simultaneously performs a rotating movement. ${ }^{24}$ Apart from age, gender, grip strength and wrist strength, the diameter of the closure and the coefficient of friction between the hand and the bottle closure are factors that affect the ability to open a bottle. ${ }^{20,28,34}$ With increasing diameter of the cap, higher grip forces can be applied. ${ }^{28}$ However, studies demonstrated that the required torque increases simultaneously with an increasing diameter of the cap. ${ }^{20,24,28,34}$ Despite the very small diameter and therefore the considerably lower opening forces of the twist-off caps compared to the other torque closures, problems in opening the stand-up pouches with twist-off caps occurred. The packaging was rated as very difficult to handle, and many of the elderly people seemed to feel uneasy with this type of packaging.

The PET bottles with the different cap diameters of $30 \mathrm{~mm}$ and $40 \mathrm{~mm}$ were rated very differently as rather negatively (only openable with effort) and openable to very easy to open, respectively. Also, the results obtained from the quantitative measurements revealed a nearly three times-reduced starting 
torque of the PET bottle with larger screw caps compared to the standard PET model. This may be attributable to the larger diameter but also the lower thread height and the additional peelable foil underneath the cap as an additional quality assurance that reduces the necessity of strong tightening. The exertion of force occurs through static friction between hand and packaging. ${ }^{24} \mathrm{~A}$ minimum frictional coefficient is required to allow a specific user group to open a certain packaging. ${ }^{20,24,28,38}$ The deeper grooves of the cap of the PET bottle with a larger screw cap caused an increased friction and let the elderly perceive gripping and opening much easier. The jar with twist-off lid included in this study required 3.5 times as much torque to be opened compared with the opening of a PET bottle with a screw cap. Schreib et al. ${ }^{24}$ determined an average applicable torque of $3.96 \mathrm{Nm}$ (range 1.65-6.27), which could be applied on an $85 \mathrm{~mm}$ closure by 71 - to 80 -year-old women. The measured starting torque of $6.08 \pm 0.51 \mathrm{Nm}$ of the evaluated jar with twist-off lid $(85 \mathrm{~mm})$ correspondingly implied great challenges for the seniors.

Peelable packaging systems demand combined application of compressive force and pulling force. ${ }^{24}$ In consequence of limitations in the gripping function of the hand in some of the elderly, exertion of sufficient force to open the peelable packaging partly caused difficulties.

As a result of the differing opening mechanisms, the two types of pouches showed significantly different opening forces and were assessed accordingly. The stand-up pouches could be evenly torn open by shear stress of the packaging material, ${ }^{29}$ which was perceived as very easy. However, in some cases, the material did not tear off in a nice line but tore transversely or even ripped off. The opening force of the pouch can be further optimized through laser perforation of the requested peel contour. In this way, a readily, controlled opening of the pouch is ensured, and a neat tear-off line is obtained. ${ }^{39}$ As a result of the very unpredictable and difficult rip of the metallized pouch with sealed seam at the upper edge, the openability of the packaging was evaluated as very poor. The quantitative measurements confirmed the fluctuating opening force progression and determined a 2.4 times higher initial force than the stand-up pouch with small indentations on each side.

The thermoformed trays were evaluated very differently. Opening of the thermoformed 'easy-toopen' tray was assessed as being achievable with a rather low force required. The enlarged tab and peeling corner were said to be easier to grip compared with the standard tray that was rated to be more difficult to open. However, the peel initiation force of the tray was quantified as 1.7 times higher than the standard tray. The slightest changes in the size of the tear tab, the material used and its geometry were found to already have a considerable effect on the force needed to open the package. ${ }^{9}$ The opening force progression among the quantified trays 'easy to open' was found to be very consistent. This can probably be attributed to a better monitoring of the sealing conditions in easy to open packages in order to avoid strong fluctuations. In addition to packaging design and properties of packaging material, the packaging process and especially the sealing process were shown to have a considerable influence on the opening characteristics of a package. ${ }^{29}$ An opening solution that juts out from the packaging, as with the containers with an aluminium foil lid, was felt to improve access to it, and the packaging was rated as openable despite the approximately same peel initiation force as the standard thermoformed tray. Because of the round shape of the container, an even peel line course was obtained, and a smooth openability was achieved with a reduced risk of spilling.

Cans were evaluated as being only openable with much effort or even not openable, consistent to the very high initial force required to pull up the ring pull of the can.

The way in which a packaging is held and the type of grip that is used when opening a packaging are strongly dependent on the size and form of the package. However, personal experiences of the consumer also influence the grip utilized and thus the exerted force. ${ }^{24}$ Studies showed limited correlation between hand force and the force applied to open packaging. However, a tendency that elderly people have to expend a higher ratio of their available strength became apparent. ${ }^{26}$ The implemented hand force measurements demonstrated that there were substantial ranges in the hand force of elderly people over 65 years old, which have to be considered in the development of senior-focused packaging. The trend that frail elderly had lower hand forces also became visible in the evaluation of the packaging types. Frail elderly encountered more difficulties in opening the examined packaging and assessed the openability generally to be poorer than active elderly. The design of packaging should therefore enable flexible utilization and the application of different sequences of movements. ${ }^{29}$ Varying hand 
sizes and grip types should be considered, and packaging is recommended to be suitable for both righthanded and left-handed use. ${ }^{40}$ The possibility of opening the package with either the right or left hand was very positively emphasized by the elderly people.

\section{CONCLUSION}

In order to design and develop appropriate packaging particularly for elderly people, it is important to take into account seniors' needs and physical abilities. Loss of grip strength, reduced dexterity, and tactility and visual and cognitive aspects are critical factors when opening packaging.

The opening force is often used as indicator for the ease of opening of packaging, and a reduction of the force is urged for an improved manageability. However, comparisons of the focus group discussions with quantitative measurements have revealed that the assessment of the openability is very subjective. From the consumer point of view, certain packaging types were considered as clearly easier to use and more appropriate in the everyday life of an elderly person than others. The accessibility was found to be not necessarily dependent on the required opening force of the packaging but was additionally very strongly influenced by various design factors and consumer's expectations as well as experience. Comparison of the distinct groups of elderly people, 'active elderly' and 'frail elderly', illustrated specific differences in the evaluation.

The very high peel initiation force of the thermoformed tray 'easy to open' demonstrated that ease of opening may be possible without restricting seal strength and thus the quality and safety of a product. This finding could have influence on the definition of appropriate design changes for improved openability of packaging, and evaluation of further food packaging systems would be interesting.

\section{ACKNOWLEDGEMENTS}

The research leading to these results has received funding from the European Union's Seventh Framework Programme for research, technological development and demonstration under grant agreement no. Kbbe311754 (OPTIFEL).

\section{REFERENCES}

1. BAGSO. Bundesarbeitsgemeinschaft der Senioren-Organisationen e.V. Beschwerdepool für ältere Verbraucher Ergebnisse der Befragung zum Thema Verpackungen, 2003.

2. Goldman A, McKay B, Mojet J, Kremer S. Scientific Information Bulletin (SIB). Meeting the food needs of the ageing population - implications for food science and technology. The International Union of Food Science and Technology (IUFoST), 2014.

3. Makely W. Pet food packaging plays to the audience; packaging convenience, visual appeal and barrier help attract pet owners - but in different ways in different stores. (Pet Food Packaging). Food \& Drug Packaging 2002 [cited 2014 February 13]; Available from: HighBeam Research: http://www.highbeam.com/doc/1G1-95149973.html.

4. Weineck J. Sportbiologie, 9th edn. GmbH \& Co KG: Spitta Verlag, 2004.

5. Meyer-Hentschel G. Nicht alle Kunden sind jung. Neue Anforderungen an Verpackungen. 2006 [cited 2014 February 13]; Available from: http://www.age-explorer.de/.

6. Snih S, Markides K, Ottenbacher K, Raji M. Hand grip strength and incident ADL disability in elderly Mexican Americans over a seven-year period. Aging Clinical and Experimental Research 2004; 16(6): 481-486. DOI:10.1007/BF03327406.

7. Ling CHY, Taekema D, de Craen AJM et al. Handgrip strength and mortality in the oldest old population: the Leiden 85plus study. Canadian Medical Association Journal 2010; 182(5): 429-435. DOI:10.1503/cmaj.091278.

8. Rantanen T, Guralnik JM, Foley D et al. Midlife hand grip strength as a predictor of old age disability. JAMA 1999; 281(6): 558-560. DOI:10.1001/jama.281.6.558.

9. Marks M, Muoth C, Goldhahn J et al. Packaging - a problem for patients with hand disorders? A cross-sectional study on the forces applied to packaging tear tabs. Journal of Hand Therapy 2012; 25(4): 387-396. DOI:10.1016/j.jht.2012.04.003.

10. Ah-Chan JJ, Downes S. The aging eye. Reviews in Clinical Gerontology 2006; 16(02): 125-139, DOI: doi:10.1017/ S0959259806002061

11. Chivers J. Care of older people with visual impairment. Nursing Older People 2003; 15(1): 22-26. DOI:10.7748/ nop2003.03.15.1.22.c2238.

12. Watkinson S. Visual impairment in older people: the nurse's role. Nursing Standard 2005; 19(17): 45-52. DOI:10.7748/ ns2005.01.19.17.45.c3782.

13. Seniorenmarketing. Empfehlungsbroschüre. Landesinitiative Seniorenwirtschaft NRW, 2006. 
14. Craik FIM, Bosman EA. Age-related changes in memory and learning. In Gerontechnology, Bouma H, Graafmans JAM (eds). IOS Press: Amsterdam, Netherlands, 1992; 79-92.

15. Kensinger EA, Corkin S. Neural changes in aging. In Encyclopedia of Cognitive Science, Nadel L (ed). Nature Publishing Group: London, 2003; 70-78.

16. Stokes G. On Being Old: The Psychology of Later Life. Falmer Press: London, 1992.

17. Chavalkul Y, Saxon A, Jerrard RN. Combining 2D and 3D design for novel packaging for older people. 2011.

18. Heiniö R, Åström A, Antvorskov H, Mattsson M, Østergaard S. Easy Open Pack - Scientific background for the basis of an international standard for easy-to-open packages. Nordic cooperation project (NICe) 2008.

19. Pro Carton, Association of European Cartonboard and Carton Manufacturers. Market research study. Packaging requirements of the over 60's, 2006.

20. Rowson J, Yoxall A. Hold, grasp, clutch or grab: consumer grip choices during food container opening. Applied Ergonomics 2011; 42(5): 627-633. DOI:10.1016/j.apergo.2010.12.001.

21. Winder B, Ridgway K, Nelson A, Baldwin J. Food and drink packaging: who is complaining and who should be complaining. Applied Ergonomics 2002; 33(5): 433-438. DOI:10.1016/S0003-6870(02)00026-1.

22. Galley M, Elton E, Haines V. Packaging: a box of delights or a can of worms? The contribution of ergonomics to the usability, safety and semantics of packaging. 2005.

23. Langley J, Yoxall A, Wearn J, Janson R. Inclusive design: making packaging easier to open for all. In 14th IAPRI World Conference on Packaging. 2004. Stockholm.

24. Schreib I, Kiese R, Liebmann A. Merkblatt No. 109/2012. Öffnungsprinzipe an Verbraucherverpackungen. Arbeitsgruppe Abfüllen und Verpacken von Lebensmitteln - AVL. Fraunhofer Anwendungszentrum für Verarbeitungsmaschinen und Verpackungstechnik, Dresden: Berlin, 2012.

25. Yoxall A, Luxmoore J, Austin M et al. Getting to grips with packaging: using ethnography and computer simulation to understand hand-pack interaction. Packaging Technology and Science 2007; 20(3): 217-229. DOI:10.1002/pts.755.

26. Rahman N, Thomas JJ, Rice MS. The relationship between hand strength and the forces used to access containers by well elderly persons. The American Journal of Occupational Therapy 2002; 56(1): 78-85.

27. Yoxall A, Janson R, Bradbury SR et al. Openability: producing design limits for consumer packaging. Packaging Technology and Science 2006; 19(4): 219-225. DOI:10.1002/pts.725.

28. Yoxall A, Janson R. Fact or friction: a model for understanding the openability of wide mouth closures. Packaging Technology and Science 2008; 21(3): 137-147. DOI:10.1002/pts.785.

29. Schreib I, Liebmann A. Merkblatt No. 106/2011. Guideline für die Gestaltung von peelbaren Verpackungen unter dem Gesichtspunkt "Easy Opening". Arbeitsgruppe Abfüllen und Verpacken von Lebensmitteln - AVL. Fraunhofer Anwendungszentrum für Verarbeitungsmaschinen und Verpackungstechnik, Dresden: Berlin, 2011.

30. Liebmann A. Easy opening. 2012 [cited 2014 February 13]; Available from: http://www.easy-opening.com/.

31. Carus DA, Grant C, Wattie R, Pridham MS. Development and validation of a technique to measure and compare the opening characteristics of tamper-evident bottle closures. Packaging Technology and Science 2006; 19(2): 105-118. DOI:10.1002/ pts. 721 .

32. Duizer LM, Robertson T, Han J. Requirements for packaging from an ageing consumer's perspective. Packaging Technology and Science 2009; 22(4): 187-197. DOI:10.1002/pts.834.

33. Langley J, Janson R, Wearn J, Yoxall A. 'Inclusive' design for containers: improving openability. Packaging Technology and Science 2005; 18(6): 285-293. DOI:10.1002/pts.699.

34. Yoxall A, Langley J, Janson R et al. How wide do you want the jar?: the effect on diameter for ease of opening for widemouth closures. Packaging Technology and Science 2010; 23(1): 11-18. DOI:10.1002/pts.874.

35. Yoxall A, Rowson J. Talking about torque: measuring pack accessibility - a review. Packaging Technology and Science 2015; 28(1): 1-14. DOI:10.1002/pts.2079.

36. Ibrahim NI, Davies S. Aging: physical difficulties and safety in cooking tasks. Work: A Journal of Prevention, Assessment and Rehabilitation 2012; 41(0): 5152-5159. DOI:10.3233/WOR-2012-0804-5152.

37. Silva DC, Paschoarelli LC, da Silva JCP. Openability of soft drinks PET packagings. Work: A Journal of Prevention, Assessment and Rehabilitation 2012; 41(0): 1346-1351. DOI:10.3233/WOR-2012-0322-1346.

38. Lewis R, Menardi C, Yoxall A, Langley J. Finger friction: grip and opening packaging. Wear 2007; 263(7-12): 1124-1132. DOI:10.1016/j.wear.2006.12.024.

39. Scheyer. 2014 [cited 2014 May 6]; Available from: http://www.sheyer.ch

40. 124:2002 D-F. Gestaltung barrierefreier Produkte. DIN Deutsches Institut für Normung e.V., 2002; -Beuth Verlag GmbH. 